\title{
BMJ Open Integrated system responses for families impacted by violence: a scoping review protocol
}

\author{
Claire Gear (D) , ${ }^{1}$ Chien-Ju Ting (D) , ${ }^{1}$ Manarah Eraki, ${ }^{1}$ Elizabeth Eppel, ${ }^{2}$ \\ Jane Koziol-McLain (i) ${ }^{1}$
}

To cite: Gear C, Ting C-J, Eraki M, et al. Integrated system responses for families impacted by violence: a scoping review protocol. BMJ Open 2021;11:e051363. doi:10.1136/ bmjopen-2021-051363

- Prepublication history for this paper is available online. To view these files, please visit the journal online (http://dx.doi. org/10.1136/bmjopen-2021051363).

Received 16 March 2021 Accepted 01 November 2021

Check for updates

(c) Author(s) (or their employer(s)) 2021. Re-use permitted under CC BY-NC. No commercial re-use. See rights and permissions. Published by BMJ.

${ }^{1}$ Centre for Interdisciplinary Trauma Research, Faculty of Health and Environmental Sciences, Auckland University of Technology, Auckland, New Zealand

${ }^{2}$ School of Government, Victoria University of Wellington, Wellington, New Zealand

Correspondence to

Dr Claire Gear;

claire.gear@aut.ac.nz

\section{ABSTRACT}

Introduction The impacts of violence have a significant effect on health and well-being, particularly for women and children. Violence within families is widely recognised as a complex problem constituted by constantly interacting and evolving social, economic, health and cultural elements. Calls for integrated services have arisen from growing understanding about the implications of this complexity, which suggest family violence and solutions to it are generated endogenously from the reflexive nonlinear interactions of system agents. Despite these calls for integration, services designed to support families impacted by violence and the systems that design and fund them are often responsive only to one part of the problem and might not pay attention to agent interactions and their adaptive reflexivity. This paper outlines a scoping protocol to explore how integrated approaches to family violence are conceptualised in current literature, with innovative use of a complexity theory lens.

Method Our scoping review protocol follows the framework outlined by Arksey and 0'Malley and refined by Levac. It searches 6 databases, 3 journals and 10 websites using keywords to capture the notion of integration and a complex adaptive system, namely the participant (system agents), concept (system agent interaction) and the context (family violence). Selection criteria require the articles to be written in English, have full-text article available, and were published after 2010. Items selected also need to be evidence based showing interaction between system agents. Applying complexity theory, sensitises us to the reflexive patterns of interaction between system elements and routine ways of interacting. Ethics and dissemination The nature of this review means that ethics approval is not required. Findings will be disseminated via academic publications, conferences and discussions with policy decision-makers. The findings will be used to develop a plan for stakeholder consultation to share and validate learnings and inform future research.

\section{INTRODUCTION}

Violence within families is widely recognised as a complex problem constituted by constantly evolving social, economic, health and cultural elements. ${ }^{12}$ The immediate and cumulative effects of violence significantly impact the health and well-being of families, particularly women and children. ${ }^{3}$ The systems

\section{Strengths and limitations of this study}

Provides a critical analysis of a policy concept often lauded as the solution.

- Applies complexity theory to provide new insights.

- Explores the impact on health services for Indigenous peoples.

- The scope of the study is limited to the focus on the interaction between system agencies.

and services designed to provide support, however, are often fragmented, responsive only to single system-level issues such as criminal justice, statutory child protection or health. This means that families seeking help must navigate multiple compartmentalised systems, often while in crisis. ${ }^{14}$ Despite repeated calls for integrated service delivery, generating care responsive to a multitude of health and social needs continues to be challenging. ${ }^{4}$ In this scoping review, we seek to understand the existing knowledge relating to the notion of an 'integrated' family violence response. Our complexity theory (CT) lens sensitises us to reflexive patterns of interaction between system elements and routine ways of interacting.

Recognising the intersecting determinants of violence, the WHO calls for a 'holistic, integrated and coordinated response across different sectors, professional disciplines, and governmental, private and nongovernmental institutions'. 4 New Zealand aspires to create an integrated approach to family violence service delivery that is more than just coordination between services, rather, all agencies and practitioners should have a collective understanding of family violence and the overall response system to respond effectively. ${ }^{1}$ However, the current New Zealand response to violence within families or whānau is characterised by an assortment of fragmented unpredictable services that are culturally inappropriate, underpinned 
by outdated theories of domestic violence and unresponsive to intersections between health and social systems. ${ }^{15}$ Whānau is an Indigenous Māori family collective based on connection, ancestry, spirituality and responsibility. ${ }^{6}$

In Aotearoa New Zealand, the Indigenous population-Māori, are disproportionately impacted by violence within whānau, with serious consequences for health and well-being. ${ }^{78}$ Similar to Indigenous peoples globally, violence within whānau stems from historical and colonial trauma, often reinforced by systems and services that perpetuate racism. ${ }^{9}$ Understanding the layers of social entrapment is critical for disrupting these patterns of violence. ${ }^{81011}$ Although the benefits of approaches that are 'by Māori, for Māori' are widely recognised, they are often marginalised by a requirement to validate outcomes within western evidence frameworks. ${ }^{12}$ Western models of integration predominantly prioritise service organisation for individual care. In contrast, kaupapa Māori (Māori culturally framed) methods focus on whānau-centred models where whānau are supported by health and social providers to self-determine the health of individuals and whānau grounded in their own cultural values. ${ }^{813}$

This scoping review focuses on how integrated approaches to family violence impact health equity. Some recent New Zealand initiatives have focused on integrating practices and systems to enable effective and safer responses to families or whānau impacted by violence. ${ }^{14-17}$ However, how to sustainably integrate prevention and intervention initiatives across wider government and non-government agencies and practices remains challenging. ${ }^{14}$ Internationally, the healthcare sector has been slow to participate in cross-agency work to reduce violence; and services addressing violence have not been well integrated into health systems. ${ }^{34}$ In this study, we review scholarly and grey literature to provide insight of what is deemed an integrated family violence response. We map how the agents involved interact with one another and how this shapes service delivery outcomes. While we aim to inform New Zealand healthcare policy and practice, the findings will be of use to other countries developing integrated service delivery approaches to violence within families.

\section{METHODOLOGY AND METHOD}

Scoping reviews are commonly used to map the literature landscape to inform health policy and practice. ${ }^{18}{ }^{19}$ Colquhoun $e t a l^{18}$ define a scoping review as 'a form of knowledge synthesis that addresses an exploratory research question aimed at mapping key concepts, types of evidence, and gaps in research related to a defined area or field by systematically searching, selecting, and synthesizing existing knowledge'. This scoping review will follow the framework laid out by Arksey and $\mathrm{O}^{\prime} \mathrm{Malley}^{20}$ and refined by Levac et $a l^{19}$ to explore the breadth of existing literature. The six stages explicated below are (1) identify the research question, (2) identify relevant studies, (3) select studies, (4) chart the data, (5) collate, summarise and report the results and (6) consultation.

Increasingly used in healthcare research, CT reconceptualises health systems as complex adaptive systems (CAS). ${ }^{21} 22$ In a CAS, system 'agents' (an individual such as a nurse or service user, or a collective such as an organisation) are constantly interacting and adapting to one another. The resulting 'co-evolution' of system agents' behaviours generate patterns of interaction that organically lead to new behaviours (self-organisation) and eventually the emergence of new system structures. ${ }^{22}$ CT views

\begin{tabular}{|c|c|c|}
\hline Field & Search terms & Databases \\
\hline Abstract + Title & $\begin{array}{l}\text { (1) Keywords for 'integrate': } \\
\text { ('Integrated response' OR 'integrated care' OR } \\
\text { integration OR integrated OR inter-agency OR } \\
\text { interagency OR cross-agency OR cross-sector OR multi- } \\
\text { agency OR multi-sectorial OR collaboration OR joined- } \\
\text { up OR cross-government OR network OR networked OR } \\
\text { 'system response' OR 'comprehensive response' OR } \\
\text { coordinated OR partnership) AND }\end{array}$ & $\begin{array}{l}\text { CINAHL, Medline (via EBSCO), Scopus, } \\
\text { Cochrane Library (via OVID), New } \\
\text { Zealand Family Violence Clearinghouse, } \\
\text { PsycINFO. }\end{array}$ \\
\hline Abstract +Title & $\begin{array}{l}\text { (2) Keywords for 'family': } \\
\text { (family OR whānau OR domestic OR children OR } \\
\text { 'intimate partner' OR tamariki OR interpersonal OR } \\
\text { familial OR intrafamilial) AND }\end{array}$ & \\
\hline $\begin{array}{l}\text { Manual search using a } \\
\text { combination of (4) and } \\
\text { other keywords in (1), (2) } \\
\text { and (3) }\end{array}$ & $\begin{array}{l}\text { (4) Indigenous: } \\
\text { Indigenous, Māori, Māori-led, whānau-centred, whānau- } \\
\text { based, 'whānau first', 'Mana Wāhine', 'Mana tāne', } \\
\text { 'whānau violence', 'kaupapa Māori' } \\
\text { (Note: Use 'Zealand' to limit to New Zealand literature) }\end{array}$ & $\begin{array}{l}\text { Informit Indigenous Collection, MAI, Te } \\
\text { Kaharoa. }\end{array}$ \\
\hline
\end{tabular}


Table 2 Inclusion and exclusion criteria

\section{Inclusion:}

\begin{tabular}{|c|c|c|}
\hline Participants & $\begin{array}{l}\text { System agents involved in responding to violence within } \\
\text { families or whānau. The 'agent' will be a collective such } \\
\text { as a professional practice discipline (nurses or doctors), } \\
\text { organisation or service (health or social). The agent(s) will be } \\
\text { characterised during the data extraction process. }\end{array}$ & $\begin{array}{l}\text { Literature that does not discuss the } \\
\text { interaction between at least two system } \\
\text { agents that provide services. Since we } \\
\text { are interested in the 'what is', not what } \\
\text { 'ought to be', this needs to be evidence- } \\
\text { based and not speculative. }\end{array}$ \\
\hline
\end{tabular}

Concept

Interaction between system agents responding to families

and whānau impacted by violence. The concept will be explored from the perspective of the healthcare system, that is, how is the healthcare system interacting with, or not interacting with, other system agents in an integrated approach?

\begin{tabular}{|c|c|c|}
\hline Context & $\begin{array}{l}\text { System responses to families or whānau impacted by the } \\
\text { following types of violence as defined in the referenced } \\
\text { literature: 'intimate partner violence', 'child abuse and } \\
\text { neglect', 'elder abuse', 'd2 'domestic violence', ', 'family and } \\
\text { sexual violence', 'violence within whānau', 'intrafamilial } \\
\text { violence'. }\end{array}$ & $\begin{array}{l}\text { Literature related to violence occurring } \\
\text { outside of familial relationships }\end{array}$ \\
\hline Types of evidence & $\begin{array}{l}\text { Reviews (eg, systematic or narrative reviews) } \\
\text { Protocols for planned studies } \\
\text { Peer-reviewed research articles } \\
\text { Policy, strategy or guidelines } \\
\text { Full-text articles }\end{array}$ & $\begin{array}{l}\text { Studies published before } 2010 \\
\text { Not written in English } \\
\text { Editorial articles } \\
\text { Abstracts or posters } \\
\text { Articles where full-text is unavailable }\end{array}$ \\
\hline
\end{tabular}

the dynamic interplay between system elements as shaping and been shaped by the responses to those impacted by violence. ${ }^{23}$ In this scoping review, we are looking for interventions and services responding to violence within families or whānau that are designed to generate interaction between system agents. This theoretical position calls attention to system parts that can be obscured by other paradigmatic perspectives. For example, a CAS approach queries how ontology and epistemology shapes the perspective of the problem framed, choice of methods and findings. ${ }^{24}$ Theoretical positioning is often not made explicit within health services research, making it difficult to understand how and if findings will be useful for the target populations and settings. ${ }^{21}$

Scoping reviews by design are systematic ${ }^{25}$ and are well suited to be combined with other analytical lens to provide a deeper understanding. Our CT lens directs our focus towards identifying and extracting characteristics of interaction between agents that give rise to patterns of outcomes. This innovative theoretical approach to a scoping review has the potential to provide a rich understanding of system interactions, contextually relevant for different service delivery settings and populations.

\section{Stage 1. Identifying the research question(s)}

The term 'integrated' has many different meanings and is applied in various ways in literature. An initial search of the literature was conducted between December 2020 and January 2021 to explore subject areas and keywords to refine the research questions. This scoping review answers the following research question:
How are integrated approaches to family and whānau violence portrayed in current literature?

Further, if, and how are health system agents portrayed in the name of an integrated approach and if, and how are Indigenous perspectives portrayed.

\section{Stage 2. Identifying relevant studies}

To answer the research question, we identify relevant literature from selected databases and sources (table 1). An additional manual search will be conducted using terms specific to the New Zealand and Indigenous context to capture our interest in Indigenous health equity.

1. Main databases: CINAHL (via EBSCO), Medline (via EBSCO), Cochrane Library (via OVID), New Zealand Family Violence Clearinghouse, PsycINFO, Scopus.

2. New Zealand and Indigenous databases: MAI, Te Kaharoa, Informit Indigenous Collection.

3. Policy documents (eg, guidelines, strategy and commissioned reports) from existing networks and leading national and international health system and domestic violence organisations including, but not limited to:

- New Zealand Family Violence Death Review Committee.

- New Zealand Ministry of Social Development.

- New Zealand Oranga Tamariki: Ministry for Children.

- New Zealand Joint Venture for Family Violence and Sexual Violence (Joint Venture).

- New Zealand Ministry of Justice.

- New Zealand Ministry of Health.

- New Zealand Māori Reference Group for the Taskforce for Action on Violence within Families. 


\begin{tabular}{|c|c|}
\hline \multirow[t]{6}{*}{ Basic information } & Title \\
\hline & Year of publication \\
\hline & Author(s) \\
\hline & Country \\
\hline & Study funding sources \\
\hline & Aim /purpose of study \\
\hline \multicolumn{2}{|l|}{ Characteristics of the study } \\
\hline & What is the dominant theoretical position (eg, kaupapa Māori, human rights) \\
\hline & What is the purpose or function of the article? \\
\hline & What definitions of violence are quoted? (descriptive) \\
\hline & Who is the outcome for? (descriptive) \\
\hline & What is the outcome? \\
\hline \multirow[t]{7}{*}{ Population } & $\begin{array}{l}\text { Who are all the agents involved in the integrated approach (such as services, disciplines and } \\
\text { service users)? (descriptive) }\end{array}$ \\
\hline & Who is the lead system agent? (descriptive) \\
\hline & What are the implicit or explicit power relations among agents? \\
\hline & $\begin{array}{l}\text { How are implicit or explicit system structures influencing the integrated approach (eg, such as } \\
\text { policy, legislation)? }\end{array}$ \\
\hline & Is healthcare delivery part of the integrated approach? Y/N (descriptive) \\
\hline & How do health system agents participate in the integrated approach? \\
\hline & How do service users participate in the integrated approach? \\
\hline \multirow[t]{4}{*}{ Concept } & What is the intervention? (descriptive; for example, the name of the intervention) \\
\hline & How is integration defined by the authors? \\
\hline & $\begin{array}{l}\text { How do system agents integrate? (descriptive; the method used to integrate, that is, } \\
\text { information transfer or standardised form, rote referral) }\end{array}$ \\
\hline & How do system agents influence health service delivery? \\
\hline \multirow[t]{3}{*}{ Context } & What types of violence are included and how are they portrayed? \\
\hline & Is health equity addressed? $\mathrm{Y} / \mathrm{N}$ \\
\hline & How is health equity integrated in the approach? \\
\hline \multirow[t]{4}{*}{ Indigenous health equity } & Is there an Indigenous component? Y/N (descriptive) \\
\hline & $\begin{array}{l}\text { How are Indigenous peoples, worldviews or concepts of health and well-being integrated in the } \\
\text { approach? }\end{array}$ \\
\hline & What is the rationale for incorporating an Indigenous component? \\
\hline & How are Indigenous outcomes measured? \\
\hline
\end{tabular}

- New Zealand Office of the Commissioner for Children.

- United States Futures without Violence.

- WHO.

- Reference lists of selected studies.

Grey literature sources, such as policies, will be searched manually using a combination of the search terms outlined in table 1. We also build a Google Programmable search and apply the keywords to the search.

We piloted the search strategy, inclusion and exclusion criteria, screening and extraction process in February 2021 with three databases (Medline, Informit Indigenous Collection and the New Zealand Family Violence Clearinghouse library). We found that in order to produce more relevant search results, keywords needed to be limited to 'title' and 'abstract' search fields. Keywords and data extraction variables were refined. Basic search functions within the New Zealand Family Violence Clearinghouse library database required using keywords that connote 'integrate' for the search, for example, 'integrated system', 'collaborate', 'inter-agency'. During the pilot study, two team members screened 40 articles randomly assigned by Covidence software ${ }^{26}$ and extracted data from 10 eligible sources. Results and conflicts were presented to the team for discussion. For our screening process, we decided to be biased towards inclusion if there was uncertainty about the eligibility of a study and we clarified our characterisation of a system agent.

Types of evidence to be included and excluded in the scoping review are outlined in table 2. Authors or agencies may be contacted for clarification if necessary. The 
reference lists of studies included for full review will be searched for additional studies.

We include literature published from January 2010 to correspond with early calls for system integration and to focus on contemporary systems and understandings of integration. In 2010, the WHO Expert Meeting on HealthSector Responses to Violence against Women report called for the development of networks and partnerships between the health sector, statutory bodies and nongovernment organisations. ${ }^{27}$ Similarly, the New Zealand Whānau Ora: Report of the Taskforce on whānau-centred initiatives that identified 'integrated and comprehensive delivery' as one of six key operational elements necessary to work towards whānau well-being. ${ }^{28}$

\section{Stage 3. Selecting studies}

To select relevant studies in the screening process, we apply Participants (Population), Concept, Context (PCC) ${ }^{25}$ for inclusion and exclusion. Although not explicit within the PCC, our search strategy outlines how we pay specific attention to Indigenous system agents and concepts of integration. Endnote ${ }^{29}$ and Covidence (extraction 2.0 ${ }^{26}$ software will be used to manage eligible literature, conduct data extraction and generate a Preferred Reporting Items for Systematic Reviews and Meta-Analyses extension for Scoping Reviews (PRISMA-ScR) flow chart. Two researchers will screen the literature with a third team member consulted on any conflicts. The inclusion and exclusion criteria for the screening process are outlined in table 2.

\section{STAGE 4. CHARTING THE DATA}

The data extraction table is designed to draw out the notion of integration presented by authors (table 3). Applying a CT analytical lens, we extract and map characteristics of agent interaction. For instance, the methods of agent interaction(s), such as shared protocols or referrals will be extracted. Various agencies, that is, service users, fundings sources, system agents are also noted.

Two reviewers will conduct data extraction and the results discussed and finalised by the research team. As the purpose of the scoping review is to map out what exists in the current literature, no quality assessment tools will be employed in this report. ${ }^{20}$

\section{Stage 5. Collating summarising and reporting the results}

Data analysis will view system agents from a CAS viewpoint, that is, interacting over time. Extracted data will be exported to $\mathrm{NVivo}^{30}$ to support the management of the analysis. Research team members will explore what themes are generated by the patterns of system agent interaction and how this may contribute to the notion of an integrated approach and how healthcare services play a part. We are also open to discovering how issues such as authority and power are exercised, how issues of health equity are included and what system agents are marginalised and why. Findings, along with a descriptive numerical summary, will inform a discussion of the key concepts portrayed in what authors of selected text have termed an integrated approach to violence within families or whānau. Reporting results will be guided by the PRISMA-ScR. ${ }^{31}$

\section{Patient and public involvement statement}

Levac et $a l^{19}$ argue for consultation to be a sixth stage of the scoping review to enhance methodological rigour in validating the findings with stakeholders. Informed by the findings of the scoping review, the research team will develop a plan for stakeholder consultation. The purposes of the consultation will include sharing preliminary findings (from stage 5), validating findings and informing future research.

\section{ETHICS AND DISSEMINATION}

This study does not involve human participants or unpublished data; therefore, approval from an ethics committee is not required. Findings will be disseminated in meetings with policy stakeholders, communities, professional networks and within academic publications and conference presentations.

Acknowledgements The authors thank Carey Manuel (Ngāti Kahungunu ki te Wairoa, Ngāti Porou) for sharing her knowledge and experience of system integration from a Māori worldview.

Contributors CG and C-JT were the primary authors of the protocol. EE and JK-M contributed to scoping review design and protocol revisions. A student scholar, ME contributed to the design and writing of the protocol. C-JT and ME piloted the study protocol. All authors approved the final protocol manuscript.

Funding This work was supported by the New Zealand Health Research Council grant number [20-1155].

Competing interests None declared.

Patient and public involvement Patients and/or the public were not involved in the design, or conduct, or reporting, or dissemination plans of this research.

Patient consent for publication Not applicable.

Provenance and peer review Not commissioned; externally peer reviewed.

Open access This is an open access article distributed in accordance with the Creative Commons Attribution Non Commercial (CC BY-NC 4.0) license, which permits others to distribute, remix, adapt, build upon this work non-commercially, and license their derivative works on different terms, provided the original work is properly cited, appropriate credit is given, any changes made indicated, and the use is non-commercial. See: http://creativecommons.org/licenses/by-nc/4.0/.

\section{ORCID iDs}

Claire Gear http://orcid.org/0000-0002-1310-0188

Chien-Ju Ting http://orcid.org/0000-0002-1201-3218

Jane Koziol-McLain http://orcid.org/0000-0003-3453-023X

\section{REFERENCES}

1 Family Violence Death Review Committee. Fifth report: January 2014 to December 2015. Wellington, New Zealand: Health Quality \& Safety Commission, 2016.

2 Young-Wolff KC, Kotz K, McCaw B. Transforming the Health Care Response to Intimate Partner Violence: Addressing "Wicked Problems". JAMA 2016;315:2517-8.

3 García-Moreno C, Hegarty K, d'Oliveira AFL, et al. The healthsystems response to violence against women. The Lancet 2015;385:1567-79.

4 World Health Organisation. Global plan of action to strengthen the role of the health system within a national multisectorial response to 
address interpersonal violence, in particular against women and girls, and against children. Geneva, Switzerland, 2016.

5 Herbert R. Learning our way forward: implementation of New Zealand's family violence strategies. Victoria University of Wellington, 2008.

6 Walker T. Whānau is whānau. In: Commission TF, ed. Victoria University of Wellington: Health Services Research Centre, 2006.

7 Wilson D, Jackson D, Herd R. Confidence and connectedness: Indigenous Māori women's views on personal safety in the context of intimate partner violence. Health Care Women Int 2016;37:707-20.

8 Dobbs T, Eruera M. Kaupapa Māori wellbeing framework: the basis for whānau violence prevention and intervention. Auckland, New Zealand: New Zealand Family Violence Clearinghouse, University of Auckland, 2014.

9 Pihama L, Cameron N, Te Nana R. Historical trauma and whānau violence. Auckland New Zealand family violence Clearinghouse. University of Auckland, 2019.

10 Kruger T, Pitman M, Grennell D. Transforming whänau violence: a conceptual framework. 2nd ed. Wellington, New Zealand: Te Puni Kokiri (Ministry of Maori Affairs), 2004.

11 Tolmie J, Smith R, Short J. Social entrapment: a realistic understanding of the criminal offending of primary victims of intimate partner violence. New Zealand Law Review 2018;2018:181-217.

12 Rolleston AK, Cassim S, Kidd J, Lawrenson R, et al. Seeing the unseen: evidence of kaupapa Māori health interventions. AlterNative: An International Journal of Indigenous Peoples 2020;16:129-36.

13 Boulton AF, Gifford HH. Whānau Ora; He Whakaaro Ā Whānau: Māori family views of family wellbeing. Int Indig Policy J 2014;5:1-18

14 Mossman E, Wehipeihana N, Bealing M. Evaluation of the family violence integrated safety response pilot: phase II final report. Wellington, New Zealand: Joint Venture Business Unit, 2019.

15 Ministry of Justice. Family violence risk assessment and management framework. Wellington, New Zealand 2017.

16 Ministry of Social Development. Family violence, sexual violence and violence within whānau: Workforce capability framework. Wellington, New Zealand 2017.

17 New Zealand Government. Family violence and sexual violence work programme, 2019. Available: https://www.justice.govt.nz/justicesector-policy/key-initiatives/reducing-family-and-sexual-violence/ work-programme/ [Accessed 17 Feb 2020].
18 Colquhoun HL, Levac D, O'Brien KK, et al. Scoping reviews: time for clarity in definition, methods, and reporting. J Clin Epidemiol 2014;67:1291-4.

19 Levac D, Colquhoun H, O'Brien KK. Scoping studies: advancing the methodology. Implement Sci 2010;5:69.

20 Arksey H, O'Malley L. Scoping studies: towards a methodological framework. Int J Soc Res Methodol 2005;8:19-32.

21 Thompson DS, Fazio X, Kustra E, et al. Scoping review of complexity theory in health services research. BMC Health Serv Res 2016;16:87.

22 McDaniel RR, Driebe DJ. Complexity science and health care management. In: Friedman L H, Goes J, Savage G T, eds. Advances in health care management: Emerald group publishing limited, 2001: 11-36.

23 Gear C, Eppel E, Koziol-Mclain J. Advancing complexity theory as a qualitative research methodology. Int J Qual Methods 2018;17:160940691878255-10.

24 Clark AM, Briffa TG, Thirsk L, et al. What football teaches us about researching complex health interventions. BMJ 2012;345:e8316-7.

25 Peters MDJ, Marnie C, Tricco AC, et al. Updated methodological guidance for the conduct of scoping reviews. JBI Evid Synth 2020;18:2119-26.

26 Covidence systematic. Review software [program. Melbourne, Australia, 2021

27 World Health Organisation. Expert meeting on health-sector responses to violence against women. Geneva, 2010.

28 Durie M, Cooper R, Grennell D. Whānau Ora: report of the taskforce on whānau-centered initatives. Wellington, New Zealand: Ministry of Social Development, 2010.

29 Endnote [program]. X7 version, 2016.

30 Nvivo 12 [program].

31 Tricco AC, Lillie E, Zarin W, et al. PRISMA extension for scoping reviews (PRISMA-ScR): checklist and explanation. Ann Intern Med 2018;169:467-73.

32 World Health Assembly. WHO global plan of action to strengthen the role of the health system within a national multisectorial response to address interpersonal violence, in particular against women and girls, and against children, 2016.

33 Family Violence Death Review Committee. Fourth annual report: January 2013 to December 2013. Wellington, New Zealand: Health Quality \& Safety Commission, 2014. 